\title{
Cinco novas espécies de Cerambycidae (Insecta: Coleoptera) da Região Neotropical e novos registros
}

\author{
Maria Helena M. Galileo ${ }^{1,3}$ \& Ubirajara R. Martins ${ }^{2,3}$
}

\author{
${ }^{1}$ Museu de Ciências Naturais, Fundação Zoobotânica do Rio Grande do Sul. Caixa Postal 1188, 90001 -970 Porto Alegre, \\ Rio Grande do Sul, Brasil. E-mail: galileo@fzb.rs.gov.br \\ ${ }^{2}$ Museu de Zoologia, Universidade de São Paulo. Caixa Postal 42494, 04218-970 São Paulo, São Paulo, Brasil. \\ E-mail: urmsouza@usp.br \\ ${ }^{3}$ Pesquisador do CNPq
}

\begin{abstract}
Five new species of Cerambycidae (Insecta: Coleoptera) from the Neotropical Region and new records. New species are described: Tessaropa elongata sp. nov. from Brazil (Rondônia) has long elytra, a character that distinguishes it from the remaining species with short elytra; Hexoplon immaculatum sp. nov. from Ecuador (Pichincha) is characterized by the red-orange general color and black legs. Eburodacrys inaequalis sp. nov. from Bolivia (Santa Cruz) has elytral apices and same-color femora that cause it to be similar to E. ayri Martins \& Galileo, 2006 and E. silviamariae Martins \& Galileo, 2006, yet it differs from either species in the black lateral spines and dorsal tubercles of pronotum and the elongate eburneuos maculae of the elytra. Coleomethia bezarki sp. nov. (Costa Rica, Guanacaste) differs from C. australis Hovore, 1987 by male pronotum without rugosities, peduculate metafemora and metatibiae entirely pubescent. Bisaltes (B.) petilus sp. nov. (Costa Rica, Guanacaste, Alajuela) is separated from B. (B.)buquetii Thomson, 1868 and $B$. (B.) fuchsi Breuning, 1971 by the more slender body appearance, the absence of dark belts on pronotum, and the absence of circular macula in the anterior third of elytra. Notes and new records are provided for: Tetraibion concolor Martins, 2006 (Bolivia: La Paz); Gnomidolon ornaticolle Martins, 1960 (Panama: Colón); Mephritus apicatus (Linsley, 1935) (Brazil: Rondônia).

KEY WORDS. Apomecynini; Eburiini; Hexoplonini; Methiini; new species.
\end{abstract}

Descrevem-se duas espécies de Methiini (Cerambycinae) nos gêneros Tessaropa Haldeman, 1847 e Coleomethia Linsley, 1940. Espécies sul-americanas de Tessaropa foram estudadas por Martins (1997). As espécies de Coleomethia foram revistas por HOVORE (1987).

Em Hexoplonini (Cerambycinae), além de descrever-se uma nova espécie em Hexoplon Thomson, 1864, apresentam-se notas em Gnomidolon Thomson, 1864 e Tetraibidion Martins, 1967. Espécies sul-americanas de Hexoplon, Gnomidolon e Tetraibidion foram revistas por MARTINs (2006).

Mephritus apicatus (Linsley, 1935), originalmente descrita do Panamá (Linsley 1935), é assinalada para o Brasil, Rondônia.

Eburodacrys inaequalis sp. nov. é descrita da Bolívia. Espécies sul-americanas de Eburodacrys White, 1853, foram estudadas por MarTins (1999), mas depois dessa publicação, várias espécies foram acrescentadas por Martins \& Galileo (2005): E. apua, E. guttata, E. xirica; por Galileo \& Martins (2006): E. aenigma, E. putia, E. silvimariae, E. ayri; e por Martins \& Galileo (2008): E. crassipes.

Em Apomecynini (Lamiinae) é descrita uma nova espécie em Bisaltes Thomson, 1868, cujas espécies forma revistas por Breuning (1971). Bisaltes (B.) continha 30 espécies pelo catálogo de Monné \& Hovore (2006). Foram acrescentadas ao gênero, Bisaltes (B.) picticornis, B. (B.) taua e B. (B.) unicolor por Galileo \&
Martins (2003) e B. (B.) sautierei por Chalumeau \& Touroult (2004). As siglas utilizadas ao longo do texto correspondem às instituições: (ACMS) American Coleoptera Museum, San Antonio; (ENPC) Eugenio Nearns Private Collection, Albuquerque, Novo México; (FSCA) Florida State Collection of Arthropoda, Gainesville; (LGBC) Coleção Larry G. Bezark, Sacramento, Califórnia; (MNKM) Museo Noel Kempff Mercado, Santa Cruz (J.E. Wappes); (MCNZ) Museu de Ciências Naturais, Fundação Zoobotânica do Rio Grande do Sul, Porto Alegre; (MZSP) Museu de Zoologia, Universidade de São Paulo, São Paulo; (USUL) Utah State University, Logan. As dimensões são fornecidas em milímetros.

\section{Cerambycinae Hexoplonini}

Hexoplon immaculatum sp. nov.

Fig. 1

Cabeça, escapo e pedicelo laranja-avermelhados. Antenômeros III a VI pretos, VII-XI vermelho-acastanhados. Pernas pretas. Fronte e vértice sem pubescência. Tubérculos anteníferos bem projetados com ápice arredondado. Escapo sem sulco interno e sem projeção externa no ápice. Protórax laranja-avermelhado. Partes laterais do protórax muito finamente 
pontuadas (25X). Pronoto e prosterno lisos, muito brilhantes. Élitros unicolores, laranja-avermelhados. Pontuação elitral com pontos simples, não crateriformes. Extremidades elitrais truncadas com espinho no ângulo externo.

Coxa e trocanteres laranja-avermelhados. Fêmures, tíbias e tarsos pretos. Ponta dos metafêmures com único espinho externo, longo.Face ventral do tórax e urosternitos alaranjados.

Dimensões holótipo macho. Comprimento total, 13,8; comprimento do protórax, 3,5; largura do protórax, 1,1; comprimento do élitro, 8,8; largura umeral, 2,5.

Material-tipo. Holótipo macho, EQUAdor, Pichincha: Hotel Inalandia (E de Santo Domingo de los Colorados), 611.V.1950, J.A. Smith leg. (MZSP, doação de L.G. Bezark).

Comentários. Hexoplon immaculatum sp. nov. distinguese prontamente de suas congêneres pelo colorido alaranjado uniforme, sem manchas nos élitros, pelos antenômeros III a VI, fêmures, tíbias e tarsos pretos.

\section{Tetraibidion concolor Martins, 2006}

Comentários. Examinamos exemplar onde cada élitro apresenta duas manchas esbranquiçadas, uma arredondada que não toca a sutura na metade anterior e faixa transversal perto do meio. É possível que se trate de variação de colorido.

Material examinado. Bolívia, La Paz: Chulumani, fêmea, 2.X. 1972, G.E. Bohart leg. (LGBC).

\section{Gnomidolon ornaticolle Martins, 1960}

Gnomidolon ornaticolle Martins, 1960: 6; Monné, 2005 (cat.); Martins, 2006: 161, fig. 177.

Comentários. A distribuição é estendida para a América Central. A diferença entre os exemplares do Panamá e os da América do Sul (Colômbia e Brasil) está nos espinhos mais curtos nos mesofêmures e nos metafêmures.

Material examinado. Panamá, Panamá: Ilha Barro Colorado, fêmea, 5-12.IV.1980, H. Wolda leg. (LGBC); ditto, fêmea, 6-12.II.1985, H. Wolda leg. (LGBC); ditto, fêmea, 17.XI.1985, H. Wolda leg., "black light" (LGBC); ditto, macho, 19-25.XII.1984, H. Wolda leg. (LGBC); Colón: Fort Sherman $\left(9^{\circ} 17^{\prime} \mathrm{N} 59^{\circ} 59^{\prime} \mathrm{W}\right)$, macho, 25.V.2001, S. Odegaard leg. "on Tontelea ovalifolia", Hippocrateaceae (MZSP).

\section{Methiini \\ Coleomethia bezarki sp. nov.}

Fig. 3

Macho. Cabeça preta exceto gula, amarelada; forte e densamente pontuada. Olhos subdivididos, lobos ligados por única fileira de omatídios não justapostos. Lobos oculares superiores tão afastados entre si quanto o diâmetro de um lobo. Antenas pretas. Escapo densamente rugoso. Antenômeros apicais lineares sem modificações de pêlos.Protórax alaranjado. Partes laterais do protórax pontuadas. Pronoto fina e transversalmente rugoso. Mesonoto alaranjado, sem sulco. Escutelo preto. Proster- no liso. Processo prosternal curvo e projetado atrás das procoxas. Mesosterno e mesepisternos amarelados. Metepimeros, metepisternos e metasterno pretos. Élitros acentuadamente deiscentes com a declividade basal amarelada e o restante da superfície preta; fina e densamente pontuados; extremidades truncadas. Ápices dos élitros atingem as metacoxas.Pernas pretas. Metafêmures longamente pedunculados; metatíbias pilosas. Urosternitos pretos e gradualmente mais largos para o ápice. Urosternitos I-IV com pontos isolados. Urosternito $\mathrm{V}$ profunda e longitudinalmente sulcado e densamente pontuado junto à orla do sulco.

Fêmea. Cabeça, mesepimeros e parte anterior dos metepisternos, profêmures exceto ápice, base dos metafêmures, amarelo-alaranjados. Élitros mais longos e menos deiscentes, atingem o meio do urosternito I. Urosternitos I-V lisos; urosternito $\mathrm{V}$ opaco no centro com vestígio de sulco longitudinal.

Dimensões holótipo macho/parátipo fêmea. Comprimento dos tubérculos anteníferos a ponta dos élitros, 3,3/3,7; comprimento do protórax, 1,0/0,9; maior largura do protórax, 1,2/ 1,2; comprimento elitral, 1,7/2,1; largura umeral, 1,4/1,4; comprimento do metafêmur, 4,2/3,5.

Material-tipo. Holótipo macho, Costa Rica, Guanacaste: Rio Naranjo, 3 km SE, 1-15.VIII.1993, F.D. Parker leg. (MZSP, doação de USUL). Parátipo fêmea, ditto, 16-31.VIII.1993, F.D. Parker leg. (USUL); parátipo fêmea, ditto, 1-9.VI.1993, F. D. Parker leg. (LGBC).

Comentários. Coleomethia bezarki sp. nov., além da distribuição geográfica mais meridional, difere de C. australis Hovore, 1987 pela coloração da cabeça e do protórax, ausência de rugosidade no pronoto dos machos, metafêmures pedunculados e clavados e metatíbias inteiramente pubescentes. Em C. australis, a cabeça e o protórax são acastanhados, o pronoto dos machos é transversalmente rugoso no ápice e na base, os metafêmures têm lados subparalelos e as metatíbias têm pêlos nos dois terços apicais.

Etimologia. O nome específico é uma homenagem a Larry Bezark, Sacramento, Califórnia, que nos enviou vultoso material para identificação.

\section{Tessaropa elongata sp. nov. Fig. 4}

Fêmea. Cabeça preta. Gula amarelada. Fronte e vértice forte e densamente pontuados. Olhos divididos. Lobos oculares superiores tão distantes entre si quanto a largura de um lobo; lobos oculares inferiores ocupam quase todo o lado da cabeça. Genas muito curtas, arredondadas na borda. Antenas pretas. Escapo gradualmente engrossado para o ápice. Flagelômeros densamente cobertos por pêlos pretos em toda a superfície. Protórax amarelado, menos terço posterior que é transversalmente enegrecido. Protórax com adelgaçamento posterior mais pronunciado do que o anterior. Lados do protórax lisos. Pronoto praticamente liso. Processo prosternal ausente. Mesosterno e mesepisternos amarelados; mesepimeros, metepisternos e metasterno, pretos. Mesonoto castanho-ama- 

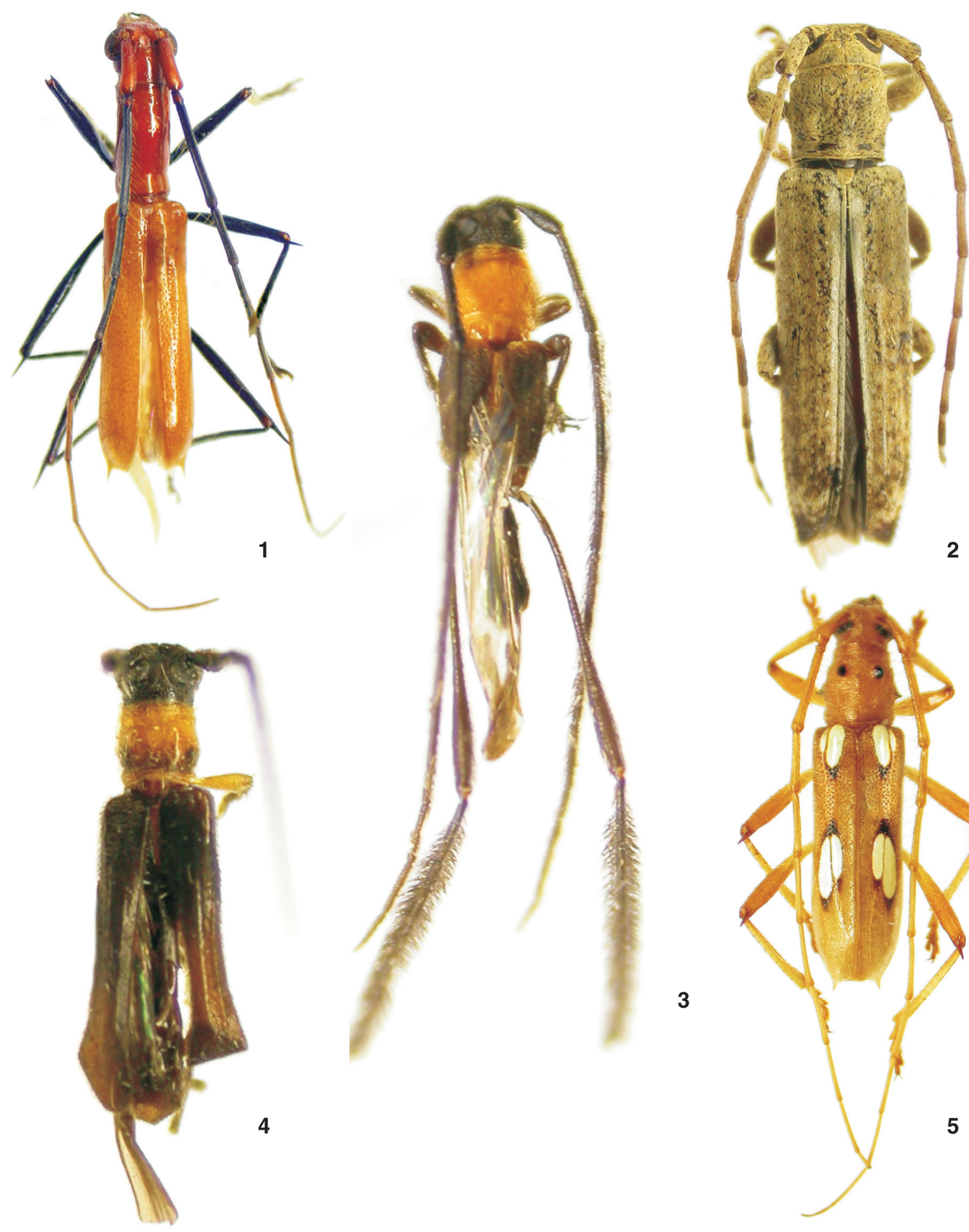

3

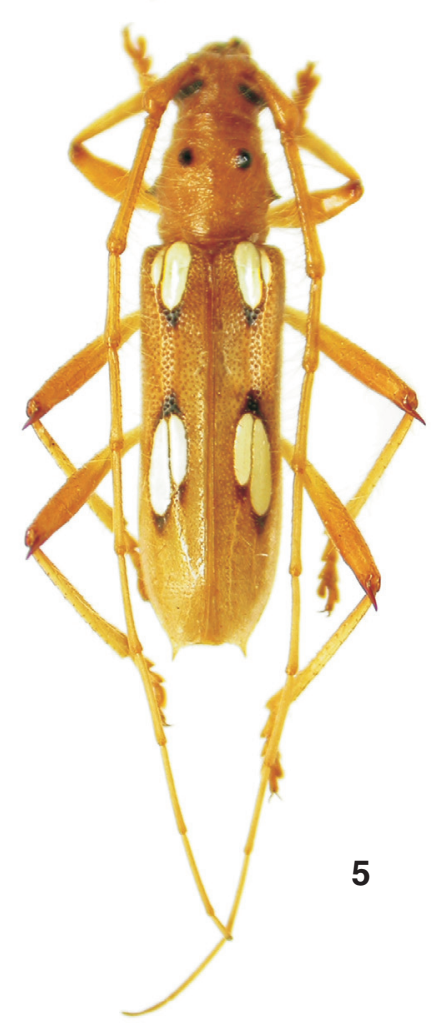

Figuras 1-5. (1) Hexoplon immaculatum sp. nov., holótipo macho, comprimento 13,8 mm; (2) Bisaltes (B.) petilus sp. nov., holótipo fêmea, comprimento 11,2 mm; (3) Coleomethia bezarki sp. nov., holótipo macho, comprimento dos tubérculos anteníferos a ponta dos élitros 3,3 mm; (4) Tessaropa elongata sp. nov., holótipo fêmea, comprimento 6,5 mm; (5) Eburodacrys inaequalis sp. nov., holótipo macho, comprimento $13,4 \mathrm{~mm}$. 
relado, sem sulco. Lados do metasterno e os metepisternos com pêlos. Escutelo preto. Élitros pretos, longos, atingem o meio do urotergito V; com abundantes pêlos curtos, pretos; duas costas próximas da sutura prolongadas até o sexto apical.Fêmures amarelados. Tíbias e tarsos pretos. Abdômen preto exceto centro dos urosternitos indistintamente mais acastanhado.

Dimensões holótipo fêmea. Comprimento total, 6,5; comprimento do protórax, 1,0; maior largura do protórax, 1,1; comprimento elitral, 4,5; largura umeral, 1,5.

Material-tipo. Holótipo fêmea, Brasil, Rondônia: Ariquemes (62 km SSE), 7-18.XI.1995, W.J. Hanson leg. (MZSP, doação de USUL).

Comentários. Tessaropa elongata sp. nov. difere das outras espécies pelos élitros mais alongados, praticamente recobrem todo o abdômen. Nas demais espécies do gênero, os élitros são curtos. Difere de T. boliviana Martins \& Galileo, 2006 também pelos élitros unicolores e pelos lados do protórax sem rugosidades. Em T. boliviana os élitros atingem a inserção dos metafêmures; a base dos élitros é amarelo-alaranjada e o restante preto, os lados do protórax têm rugas finas.

Distingue-se de T. guanabarina Martins, 1981 pelos tubérculos anteníferos, antenas, élitros e tarsos pretos; em $T$. guanabarina os tubérculos anteníferos e os tarsos são amareloalaranjados, as antenas e os élitros são pretos e amarelos.

Etimologia, Latim, elongata = longo, alusivo ao comprimento dos élitros.

\section{Elaphidionini \\ Mephritus apicatus (Linsley, 1935)}

Mephritus apicatus Linsley, 1935: 140; Monné, 2005: 221 (cat.)

Comentários. Descrita com base em exemplares procedentes do Panamá, assinala-se a ocorrência na América do Sul.

Material examinado. BrasiL, Rondônia: Ariquemes, macho, 22-31.X.1997, J.W. Hanson leg. (LGBC).

\section{Eburiini \\ Eburodacrys inaequalis sp. nov.}

Fig. 5

Colorido geral alaranjado. Vértice com microescultura e pontos muito esparsos, rasos. Antenas dos machos atingem as extremidades elitrais no ápice do VII e, nas fêmeas, na base do IX. Escapo subcilíndrico com sulco raso na base. Protórax com espinho lateral preto, mais longo que o pedicelo. Pronoto com dois tubérculos manifestos, pretos, na metade anterior; ligeiramente para atrás dos tubérculos, uma área central brilhante, restante do disco pronotal rugoso e microesculturado. Mesosterno sem tubérculo. Cada élitro com manchas ebúrneas: uma elíptica na base; ao lado externo dessa mancha, uma mácula estreita; duas contíguas no meio, a externa ultrapassa posteriormente a interna e, anteriormente, ultrapassa ligeiramente, inicia-se no mesmo nível ou ligeiramente atrás da mancha interna. Manchas pretas atrás das manchas basais e anterior e posteriormente às manchas centrais. Epipleuras ebúrneas. Extremidades elitrais truncadas com espinho curto no lado externo e concolor. Mesoe metafêmures com espinhos apicais concolores.

Dimensões macho/parátipo fêmea. Comprimento total, 13,4-17,5/11,8-15,5; comprimento do protórax, 3,3-3,9/2,3-3,1; maior largura do protórax, 3,3-4,3/2,7-3,7; comprimento elitral, 10,0-12,2/8,3-10,9; largura umeral, 3,5-4,5/2,8-3,9.

Material-tipo. Holótipo macho, Bolívia, Santa Cruz: Reserva Natural Potrerillo del Guenda $\left(17^{\circ} 40,26^{\prime} \mathrm{S} 63^{\circ} 27,43^{\prime} \mathrm{W}\right.$, 400 m), 16-21.X.2006, Nearns, Wappes \& Eya leg., luz ultravioleta (MNKM).

Parátipos: mesmos dados do holótipo, duas fêmeas (ACMS, MCNZ); Reserva Natural Potrerillo del Guenda $\left(17^{\circ} 40,26^{\prime} \mathrm{S} 63^{\circ} 27,43^{\prime} \mathrm{W}, 400 \mathrm{~m}\right.$, Snake farm), macho, 1622.X.2006, Nearns, Wappes \& Eya leg., (ACMS); Buena Vista (Hotel Flora \& Fauna, 430 m), macho, fêmea, 5-15.XI.2001, M.C. Thomas, B.K. Dozier leg., "tropical transition forest, black light trap" (FSCA); (Hotel Flora \& Fauna, 4,6 km SSE, $430 \mathrm{~m}$ ), macho, 22-25.X.2007, Galileo \& Martins leg. (MZSP); (Hotel Flora \& Fauna, 4-6 km SSE), fêmea 19-22.X.2004, Wappes \& Morris leg. (ACMS); (Hotel Flora \& Fauna, 350 m), fêmea, 14.XI.2003, Nearns, Morris \& Wappes leg. (ENPC).

Comentários. Eburodacrys inaequalis sp. nov. tem máculas elípticas nos élitros, ápices dos élitros e dos meso- e metafêmures concolores assim como em E. ayri Galileo \& Martins, 2006 e E. silviamariae Galileo \& Martins, 2006. Distingue-se de E. silviamariae pelos espinhos laterais do protórax pretos, pelos ápices elitrais com único espinho externo, pelas manchas ebúrneas basais alongadas e acompanhadas por outra mancha estreita no lado externo. Em E. silviamariae, os espinhos laterais do protórax são concolores, os ápices elitrais têm dois espinhos curtos, as mancha ebúrneas basais são mais arredondadas e não estão ladeadas de mancha ebúrnea estreita.

Difere de E. ayri pelos espinhos laterais e dorsais do protórax pretos, pelas manchas ebúrneas basais dos élitros alongadas e acompanhadas por outra mancha estreita no lado externo, pelo espinho externo do ápice dos élitros alongado. Em E. ayri os espinhos dos lados do protórax e do pronoto são concolores, as manchas ebúrneas na base dos élitros são elípticas e não estão ladeadas por mancha ebúrnea estreita e o espinho no ápice dos élitros é muito curto.

\section{Lamiinae Apomecynini Bisaltes (B.) petilus sp. nov.}

Fig. 2

Cabeça revestida por pubescência amarelada. Lobos oculares superiores com quatro fileiras de omatídios, tão distantes entre si quanto o quádruplo da largura de um lobo. Antenas, nos machos, atingem a declividade apical dos élitros. Escapo revestido por pubescência amarelada e cicatriz escurecida. Antenômeros IV, V, VII e IX com pubescência esbranquiçada e anel apical acas- 
tanhado; VI, VIII e X acastanhados com anel basal de pubescência esbranquiçada. Protórax com pubescência amarelada sem faixas longitudinais pretas, partes laterais com alguns pontos contrastantes.Élitros com friso sutural coberto por pubescência esbranquiçada; no restante da superfície, menos nos ápices, com pubescência predominantemente amarelada; uma faixa anteapical de pubescência esbranquiçada e ápice com pubescência preta. Pêlos elitrais pretos. Extremidades elitrais obliquamente truncadas com espículo externo. Mesosterno sem tubérculo, truncado adiante do processo mesosternal. Esternos meso- e metatorácicos com pubescência amarelada. Pro- e mesofêmures com pubescência amarelada e alguns pontos contrastantes; metafêmures com pubescência amarelada, mancha preta no lado inferior da metade basal e alguns pontos contrastantes. Pro- e mesotíbias com pubescência amarelada; metatíbias pretas, engrossadas nos machos. Urosternitos com pubescência amarelada e manchas a cada lado: urosternito I com única mancha preta, II a IV com duas manchas pretas, uma lateral e uma mais para o meio; urosternito $\mathrm{V}$ com pubescência preta nas bordas.

Dimensões macho/fêmea. Comprimento total, 7,5-8,9/ 9,2-11,2; comprimento do protórax, 1,4-1,5/1,8-2,0; maior largura do protórax, 1,6-1,9/2,2-2,3; comprimento elitral, 5,5-6,6/ 7,7-8,6; largura umeral, 1,8-2,2/2,5-2,9.

Material-tipo. Holótipo fêmea, Costa Rica, Guanacaste: Rio Naranjo (3 km SE), 8-10.II.1992, S.D. Parker leg. (MZSP, doação de USUL). Parátipos: Costa Rica, Guanacaste, Rio Naranjo (3 km SE), fêmea, 21-31.I.1992, S. D. Parker leg. (MCNZ); Rio Naranjo (3 km SE), macho, 10-20.IX.1992, S.D. Parker leg. (LGBC). Alajuela: Upala (20 km S), macho, 1.VIII.1990, S.D. Parker leg. (USUL).

Comentários. Bisaltes (B.) petilus sp. nov. difere de Bisaltes (B.) buquetii Thomson, 1868 e B. (B.) fuchsi Breuning, 1971 pelo aspecto geral mais esbelto, pela ausência de faixas escuras no pronoto, ausência de mancha acastanhada circular, sutural no terço anterior dos élitros, sutura com pubescência esbranquiçada, mancha escura na ponta dos élitros em toda a extensão. Em B. (B.) buquetii e B. (B.) fuchsi a conformação é mais robusta, o pronoto tem duas faixas centrais e duas laterais de pubescência acastanhada, os élitros apresentam mancha acastanhada circular, sutural no terço anterior dos élitros, a sutura elitral não é revestida por pubescência esbranquiçada e a mancha escura na ponta dos élitros está restrita às partes laterais.

Distingue-se de B. (B.) fuscoapicalis Breuning, 1950 pelos lobos oculares superiores afastados entre si por distância igual ao quádruplo da largura de um lobo, pela ausência de faixas longitudinais e escuras no pronoto, pela pubescência dos élitros unicolor e friso sutural com pubescência esbranquiçada, extremidades elitrais sem espículo no ângulo externo. Em B. (B.) fuscoapicalis os lobos oculares superiores mais próximos entre si do que a largura de um lobo, pronoto com duas faixas longitudinais acastanhadas, os élitros têm pubescência marmoreada amarelada e acastanhada e o friso não tem pubescência branca, as extremidades elitrais são acastanhadas e têm espículo no ângulo externo.

\section{AGRADECIMENTOS}

À Eugenio Nearns (ENPC), James E. Wappes (ACMB) e Larry G. Bezark (LGBC) pelo empréstimo de material para estudo. À Eleandro Moyses (MCNZ) pelas fotografias e digitalização das imagens.

\section{LITERATURA CITADA}

BREUning, S. 1971. Revision des espèces américaines de la tribue des Apomecynini Lac. Entomologische Abhandlungen Staatliches Museum Tierkunde in Dresden 37(3): 209-335.

Chalumeau, F. \& J. Touroult. 2004. Um nouveau lamiaire de Guadelouope. Lambillionea 104: 64-65.

Hovore, F.T. 1987. A review of the genus Coleomethia Linsley [Coleoptera: Cerambycidae]. The Wasmann Journal of Biology 45 (1-2): 6-15.

Galileo, M.H.M. \& U.R. Martins. 2003. Notas e descrições em Bisaltes Thomson, 1868 e Ptericoptus Lepeletier \& AudinetServille, 1830 (Lamiinae, Apomecynini). Revista Brasileira de Entomologia 47 (3): 379-383.

Galileo, M.H.M. \& U.R. Martins. 2006. Notas e descrições em Eburiini (Coleoptera, Cerambycidae). Iheringia, Série Zoologia, 96 (2): 179-184.

LinSLEY, E.G. 1935. Notes and descriptions of new or little known neotropical Sphaerionini. Revista de Entomologia 5 (2):139-149.

Martins, U.R. 1960. Ibidionini V. Comentários e descrição de novas espécies do gênero Gnomidolon Thomson. Papéis Avulsos de Zoologia 14 (1):1-10.

Martins, U.R. 1997. Cerambycidae Sul-Americanos (Coleoptera). São Paulo, Sociedade Brasileira de Entomologia, vol. $1,217 \mathrm{p}$.

Martins, U.R. 1999. Cerambycidae Sul-Americanos (Coleoptera). São Paulo, Sociedade Brasileira de Entomologia, vol. $3,418 \mathrm{p}$.

Martins, U.R. 2006. Cerambycidae Sul-Americanos (Coleoptera) taxonomia. São Paulo, Sociedade Brasileira de Entomologia, vol. 8, 234p.

Martins, U.R. \& M.H.M. Galileo. 2005. Novos táxons e notas sobre Cerambycidae da região Neotropical. Revista Brasileira de Zoologia 22 (3): 764-770.

Martins, U.R. \& M.H.M. Galileo. 2008. Novos Cerambycidae (Coleoptera) da Coleção Odette Morvan, Guiana Francesa. II. Papéis Avulsos de Zoologia 48 (8): 55-59.

Monné, M.A. 2005. Catalogue of the Cerambycidae (Coleoptera) of the Neotropical Region. Part I. Subfamily Cerambycinae. Zootaxa 946: 1-765.

Monné, M.A. \& F.T. Hovore. 2006. Checklist of the Cerambycidae, or longhorned wood-boring beetles, of the Western Hemisphere. Rancho Dominguez, BioQuip, 394p.

Submitted: 21.VII.2008; Accepted: 26.I.2009.

Editorial responsibility: Gabriel Mejdalani 